Las Radios de La Reforma

Aldo Rotman

Question/Cuestión, Vol. 2, №66, Agosto 2020

ISSN 1669-6581

https://perio.unlp.edu.ar/ojs/index.php/question/index

IICom-FPyCS-UNLP

\title{
LAS RADIOS DE LA REFORMA
}

\section{THE RADIOS OF THE REFORM}

\section{Aldo Rotman}

Coordinador general de Comunicación y Medios de la Universidad Nacional de Entre Ríos

Docente de la Carrera de Licenciatura en Comunicación Social

Presidente de ARUNA aldo.rotman@uner.edu.ar Instagram: @aldorotman

Twitter: @AldoRotman

\section{Resumen}

Aldo Rotman destaca el valor de las emisoras universitarias argentinas.

\section{Palabras clave}

Radios Universitarias, Institucionalidad, ARUNA 


\section{Abstract}

Aldo Rotman highlights the value of Argentine university radio stations

\section{Keywords}

University Radios, Institutionality, ARUNA

\section{Enlace}

https://go.ivoox.com/rf/55656748 